\title{
Diversity in the practice of district ethics committees
}

\author{
Claire Gilbert, K W M Fulford, C Parker
}

\begin{abstract}
A survey of ethics committees in district health authorities was carried out to find out the size and make up of committees and what information and guidance they offered to scientists who apply to do research. A sample $(n=28)$ of committees in England $(n=190)$, half from teaching districts and half from non-teaching districts, was contacted by post requesting this information. A high degree of diversity was found, not only in the methods that committees used but also in the ethical criteria each considered to be pertinent for research. It was also shown that published guidelines have made little impact. It is suggested that issuing more guidelines will be of limited use. Rather, the following are needed: information about why guidelines have been widely ignored, better communication between committees, some form of education for committee members, and a formal register of committees compiled.
\end{abstract}

\section{Introduction}

The function of research ethics committees is to ensure that those who carry out medical research take due note of ethical considerations. The increasing public concern about the ethical implications of medical research emphasises the importance of these committees. Recently, organisations have been issuing advice to potential participants in trials, such as the National Childbirth Trust's advice to pregnant women who are asked to be subjects in research trials.

The Medical Research Council reported on ethics in research in 1963, emphasising the moral responsibility of researchers for their subjects. ${ }^{2}$ In 1967 the Royal College of Physicians published a statement recommending that research be subject to ethical review. ${ }^{3}$ In 1968 the Ministry of Health circulated a memorandum, with a copy of the Royal College of Physician's statement, to regional hospital boards, hospital management committees, and boards of governors suggesting that hospital authorities should organise ethical review boards on an informal, advisory basis. ${ }^{4}$ But authorities were not legally required to establish ethics committees, and the committees were offered no formal legal status. No specific guidelines on practices and methods were given because it was thought that strict rules of conduct would not be adaptable to local needs.

Ethics committees were then created haphazardly and idiosyncratically: the rate at which health authorities responded was variable; some research institutions and some pharmaceutical companies set up their own committees; and some committees were set up by independent bodies. No central register has been compiled and there is, therefore, no network for circulating information and guidelines.

Statements of ethical principles and guidelines relevant to research, ${ }^{5-14}$ discussions on various ethical points, ${ }^{15-17}$ and examples of difficulties which ethics committees come across ${ }^{18-20}$ have been published in Britain. In 1984 the Royal College of Physicians published guidelines (now being updated) specifically for ethics committees. ${ }^{10}$ These cover, for example, accountability, size and make up, methods of assessment, and problems with certain kinds of research. Two years after these guidelines were issued the Institute of Medical Ethics conducted a survey of ethics committees in the United Kingdom as part of a study of research on children ${ }^{21}$ which showed that there was much diversity among ethics committees and that much of the advice of the Royal College of Physicians was not being followed.

Because of the worrying results of that survey, the growing public concern over the ethical aspects of medical research, and the proliferation of ethics committees it is important to know how these committees function. The purpose of this survey was to find out $(a)$ the size and make up of research ethics committees in district health authorities; $(b)$ the number of research proposals submitted to committees for approval; and $(c)$ what information and guidance committees give to research workers. A further aim was to find out how the different committees worked.

\section{Methods}

From the list in the Hospitals and Health Services Year Book one teaching district and one non-teaching district were selected from each regional health authority. If there was a choice it was made arbitrarily. District ethics committees were chosen over other kinds of ethics committees because they were more accessible and also more likely to be comparable. The sample represents 14 of $23(61 \%)$ ethics committees in teaching districts and 14 of $167(8 \%)$ ethics committees in non-teaching districts $-15 \%$ of all district ethics committees (28 of 190).

We contacted each chairman by post and asked for a copy of the application form used by the committee and information on the make up of the committee (without the names of members). We telephoned those who did not reply and asked for the same information. We later requested the number of research applications each committee had received in 1988. We received information from all 28 committees on the three aspects we wished to study and also on ethical considerations.

\section{Results}

Size and make up of committees (table I)

The number of members on committees varied from four to 22 . All 28 committees had hospital consultants, 21 had general practitioners, only one (non-teaching district) committee had no lay member, and one had an "observer" from a community health council but no voting lay member. Sixteen committees had a practis- 
ing nurse - that is, a nurse in "active practice with patients" 10 - four had a lawyer, and 11 had a pharmacist.

Number of research applications received in 1988 (table I) The number of applications for research submitted to all of the ethics committees in 1988 ranged from eight to 400 . More of the medical research undertaken in 1988 was approved by committees from teaching districts than by those from non-teaching districts. The results suggest that of the committees that meet to discuss applications some will have fewer than five to consider at one meeting while others may have 30 or 40 to consider.

\section{Amount of printed information for applicants (table I)}

Seven ethics committees in non-teaching districts provided no printed information, while one committee in a teaching district provided 4250 words. The most extensive amount of information comprised notes and guidelines and long forms with detailed questions to applicants. Some committees included separate sheets for applicants to complete with letters to potential volunteers, letters to the general practitioners of volunteers, an estimation of how much use of health authority resources the research would require, and other details relevant to the project. Some committees requested that such information be appended. One

TABLE I-Some characteristics of the 28 ethics committees

Committees in

Committees in

All committees teaching districts $(n=14) \quad$ non-teaching districts $(n=14)$

\begin{tabular}{|c|c|c|c|}
\hline Size (No of people) & $4-22$ & $5-22$ & $4-15$ \\
\hline No of lay members & $0-4$ & $1-4$ & $0-2$ \\
\hline No of applications received in 1988 & $8-400$ & $140-400$ & $8-250$ \\
\hline $\begin{array}{l}\text { No of words in their printed } \\
\text { guidelines }\end{array}$ & $0-4250$ & $250-4250$ & $0-2500$ \\
\hline
\end{tabular}

TABLE II - Published reports on ethical research recommended to applicants

\begin{tabular}{|c|c|c|c|}
\hline Published reports & $\begin{array}{l}\text { All committees } \\
(\mathbf{n}=28)\end{array}$ & $\begin{array}{l}\text { Committees in } \\
\text { teaching districts }\end{array}$ & $\begin{array}{c}\text { Committees in } \\
\text { non-teaching districts }\end{array}$ \\
\hline \multicolumn{4}{|l|}{ Medical Research Council: } \\
\hline $\begin{array}{l}\text { Responsibility in investigations on human } \\
\text { subjects }(1962-3)^{2}\end{array}$ & 1 & 1 & 0 \\
\hline \multicolumn{4}{|l|}{ Royal College of Physicians: } \\
\hline $\begin{array}{l}\text { Supervision of the Ethics of Clinical Research } \\
\text { Investigations in Institutions }(1967,1973)^{3}\end{array}$ & 1 & 1 & 0 \\
\hline \multicolumn{4}{|l|}{ Department of Health and Social Security: } \\
\hline $\begin{array}{l}\text { Supervision of the Ethics of Clinical Research } \\
\text { Investigations and Fetal Research }(1975)^{\circ}\end{array}$ & 1 & 1 & 0 \\
\hline \multicolumn{4}{|l|}{ World Medical Association: } \\
\hline Declaration of Helsinki $(1964,1975,1983)^{5}$ & 5 & 5 & 0 \\
\hline \multicolumn{4}{|l|}{$\begin{array}{l}\text { BMA, Royal College of General Practitioners, } \\
\text { and Association of British Pharmaceutical } \\
\text { Industries: }\end{array}$} \\
\hline Code of practice $(1983)^{?}$ & 1 & 1 & 0 \\
\hline \multicolumn{4}{|l|}{ Royal College of Physicians: } \\
\hline $\begin{array}{l}\text { Guidelines on the Practice of Ethics Committees } \\
\text { in Medical Research }(1984)^{111}\end{array}$ & 6 & 5 & 1 \\
\hline \multicolumn{4}{|l|}{ Department of Health and Social Security: } \\
\hline $\begin{array}{l}\text { Administration of Radioactive Substances to } \\
\text { Persons }(1984)^{4}\end{array}$ & 1 & 1 & 0 \\
\hline \multicolumn{4}{|l|}{ Royal College of Physicians: } \\
\hline Research on healthy volunteers $(1986)^{12}$ & 1 & 1 & 0 \\
\hline
\end{tabular}

TABLE III-Mention of ethical criteria in information provided for applicants. Values are numbers (percentages)

\begin{tabular}{lccc}
\hline & $\begin{array}{c}\text { All committees } \\
(\mathbf{n}=28)\end{array}$ & $\begin{array}{c}\text { Committees in } \\
\text { teaching districts }(\mathbf{n}=14)\end{array}$ & $\begin{array}{c}\text { Committecs in } \\
\text { non-teaching districts }(\mathbf{n}=14)\end{array}$ \\
\hline $\begin{array}{l}\text { Advances in biomedical knowledge } \\
\text { Scientific quality (design of study) }\end{array}$ & $8(29)$ & $5(36)$ & $3(21)$ \\
No of subjects needed for study & $17(61)$ & $12(86)$ & $3(21)$ \\
Competence of investigator & $5(18)$ & $14(100)$ & $3(21)$ \\
$\begin{array}{l}\text { Background to research } \\
\text { Risks and inconvenience to }\end{array}$ & $14(50)$ & $3(21)$ & $2(14)$ \\
$\quad$ subjects & $19(68)$ & $10(71)$ & $4(29)$ \\
$\begin{array}{l}\text { Informed consent } \\
\text { Use of non-autonomous subjects }\end{array}$ & $21(75)$ & $13(93)$ & $6(43)$ \\
$\begin{array}{l}\text { Confidentiality } \\
\text { Committee as facilitator of good }\end{array}$ & $8(29)$ & $14(100)$ & $7(50)$ \\
$\quad$ research & $2(7)$ & $8(57)$ & $1(7)$ \\
\hline
\end{tabular}

committee provided an example of an explanation to volunteers. Most of the brief forms (up to 500 words) asked for the name and position of the responsible investigator, the name of the project, and a summary of the protocol. Some of the shorter forms included a list of points which the applicant was to cover in the protocol or summary. Ethical considerations were sometimes included in these lists.

Seven committees (all non-teaching) had no form or guidelines and referred to the protocol only. The chairman of three of these committees said that they held no meetings. In one case the protocol was sent to each member of the committee who indicated approval by signing it; in another the chairman sent copies of the "relevant" parts of the protocol to members; in the third the chairman decided whether the research proposal required the consideration of the rest of the committee: if the application was "straightforward" enough the chairman gave his approval without reference to the rest of the committee.

Sources of guidance on the ethics of research recommended by committees (table II)

Only nine committees (seven from teaching districts and two from non-teaching districts) referred applicants to published discussions and guidelines on ethical research: six to the Royal College of Physicians' guidelines $(1984)^{10}$ and five to the Declaration of Helsinki. ${ }^{5}$ Several other documents were mentioned only once (table II)

\section{Ethical considerations mentioned in printed information (table III)}

The list of ethical criteria in table III was partly taken from the Royal College of Physicians' guidelines. ${ }^{10}$ "Informed consent" was the only criterion mentioned by all the committees that provided information. Two of the committees omitted to mention "risks and inconvenience." All the committees from teaching districts and three from non-teaching districts asked how many subjects would be needed for the research.

\section{Discussion}

There is room for some diversity among ethics committees because of the subjective nature of ethical considerations and local needs. The results of this survey of district ethics committees, however, highlight a worrying degree of variation both in the guidance given to research workers and in the information asked of them. Furthermore, the results suggest that many committees are not functioning adequately, and that the guidelines proposed by the Royal College of Physicians in 1984, which are being updated, have been widely ignored.

Such diversity causes problems in, for example, multicentre trials, which need to be approved by loca ethics committees. Some trials have been delayed in some centres when approval was not given but have gone ahead in others where local committees do not require the same ethical standards to be met by researchers. If a national ethics committee for multicentre trials existed it might facilitate the conduct of such trials, but the central question of what causes the wide variation in the way these committees function remains.

There is no point in issuing more guidelines at present, as previous ones have had little effect in practice. We suggest the following measures: firstly, a system of registering committees is needed to facilitate communication; secondly, more information needs to be gathered about why committees have not adopted the proposed guidelines; thirdly, training of potential committee members might usefully be carried out. 
Unless the practice of these committees is generally improved and made more uniform across districts it is likely that guidelines will be legally enforced for all committees, especially as public concern over ethics in research grows.

We thank Dr R A Hope and Mrs Caroline Miles for their invaluable help and encouragement.

1 National Childbirth Trust. Clinical trials and medical research-helping you decide. London: NCT, 1988.

2 Medical Research Council. Responsibility in investigations on human subjects. Report of the MRC for the year 1962-3. London: HMSO, 1964:21-5. (Cmnd 2382.)

3 Royal College of Physicians. Supervision of the ethics of clinical research investigations in institutions. London: HMSO, 1967 (updated 1973).

4 Ministry of Health. Supervision of the ethics of clinical research. London: HMSO, 1968. (HM (68) 33.)

5 World Medical Association. Declaration of Helsinki: recommendations guiding physicians in biomedical research involving human subjects. Helsinki: WMA, 1964 (amended Tokyo 1975 and Venice 1983).

6 Department of Health and Social Security. Supervision of the ethics of clinical research investigations and fetal research. London: HMSO, 1975. (HSC (1S) 153.)

7 British Medical Association, Royal College of General Practitioners, and Association of British Pharmaceutical Industries. Code of practice for the clinical assessment of licensed medicinal products in general practice. BrMed f 1983;286:1295-7.

8 Association of British Pharmaceutical Industries. Guidelines: clinical trialscompensation for medically induced injury. London: ABPI, 1983.

9 Department of Health and Social Security. Administration of radioactive substances to persons. London: HMSO, 1984. (HN (84) 5.)

10 Royal College of Physicians. Guidelines on the practice of ethics committees in medical research. London: RCP, 1984

11 British Medical Association Central Ethical Committee. Improving the network of local ethical research committees and the establishment of a national ethical research committee. London: BMA, 1986.

12 Royal College of Physicians. Research on healthy volunteers. $\mathcal{J} R$ Coll Physicians Lond 1986;20:243-7.

3 Association of British Pharmaceutical Industries. Guidelines for medical experiments in non-patient human volunteers. London: ABPI, 1988.

14 Association of Independent Clinical Research Contractors. Guidelines for research ethics committees. Cardiff: AICRC, 1989.

15 King J. Informed consent. Institute of Medical Ethics Bulletin 1986; suppl 3. 16 Diamond $\mathrm{AL}$, Laurence DR. Compensation and drug trials. $\mathrm{Br} \mathrm{Med} f$ 1983;287:675-7.

17 Lord Scarmen. Consent, communication and responsibility $\mathcal{f} R$ Soc Med 1986;79:697-700.

18 Thompson IE, French K, Melia KM, Boyd KM, Templeton AA, Potter B. Research ethical committees in Scotland. BrMed f 1981;282:718-20.

19 Anonymous. Local ethics committees [Editorial]. Br Med f 1981;282:1010.

20 Wells FO, Griffin JP. Ethics committees for clinical research: experience in the UK. Drugs 1989;37:229-32.

21 Nicholson RH, ed. Medical research on children: ethics, law and practice. Oxford: Oxford Medical Publications, 1986.

(Accepted 29 September 1989)

\section{Housing and Health}

\section{Noise, space, and light}

\section{Stella Lowry}

Earlier in this series I discussed how hard it is to prove that any given aspect of housing is harmful to health. But often that is the wrong approach anyway. Houses should not be designed just to prevent harm to their occupants but also to promote health. In this article I will discuss three aspects of housing that affect wellbeing - noise, space, and light-but differ in the obviousness of their effects.

\section{Noise}

The structure of a building determines how well it transmits sound. Airpaths over or through party walls and unsealed pores in masonry transmit airborne sound. Ties in cavity walls can conduct sound, especially if mortar droppings are not cleaned off them during construction. Lightweight plastic ceilings on upper stories can cause reverberation in the roof space. Non-rigid layers attached to walls or floors can vibrate and reduce party wall insulation.

Though building regulations govern the transmission of sound between buildings, a recent study of newly completed but unoccupied houses gave poor results.' Over 1200 party walls and about 500 party floors were tested, and over half of the walls failed to meet the Building Research Establishment's recommended standard for the transmission of sound. The performance of a third of the floors was "very poor" for insulation of sounds caused by impact.

Noise is defined as unwanted sound. People are usually very tolerant of sounds they make themselves, but when they have no control over the source or if the sound is unwelcome it becomes noise. People vary in their ability to tolerate noise. Old people are often particularly sensitive, even at low intensities, probably because their reduced hearing acuity makes them less able to select out particular sounds from the background noise. This then interferes with their ability to communicate effectively. ${ }^{2}$

Different types of noise cause different responses. In a recent review Mant and Gray concluded that traffic noise and impersonal sounds such as machines are often tolerated well. ${ }^{3}$ One of the most irritating noises is human voices, and surprisingly the intensity of a sound is of little importance in determining the annoyance it causes.

In contrast to industrial exposure the problem of domestic noise is not one of a risk to hearing - although

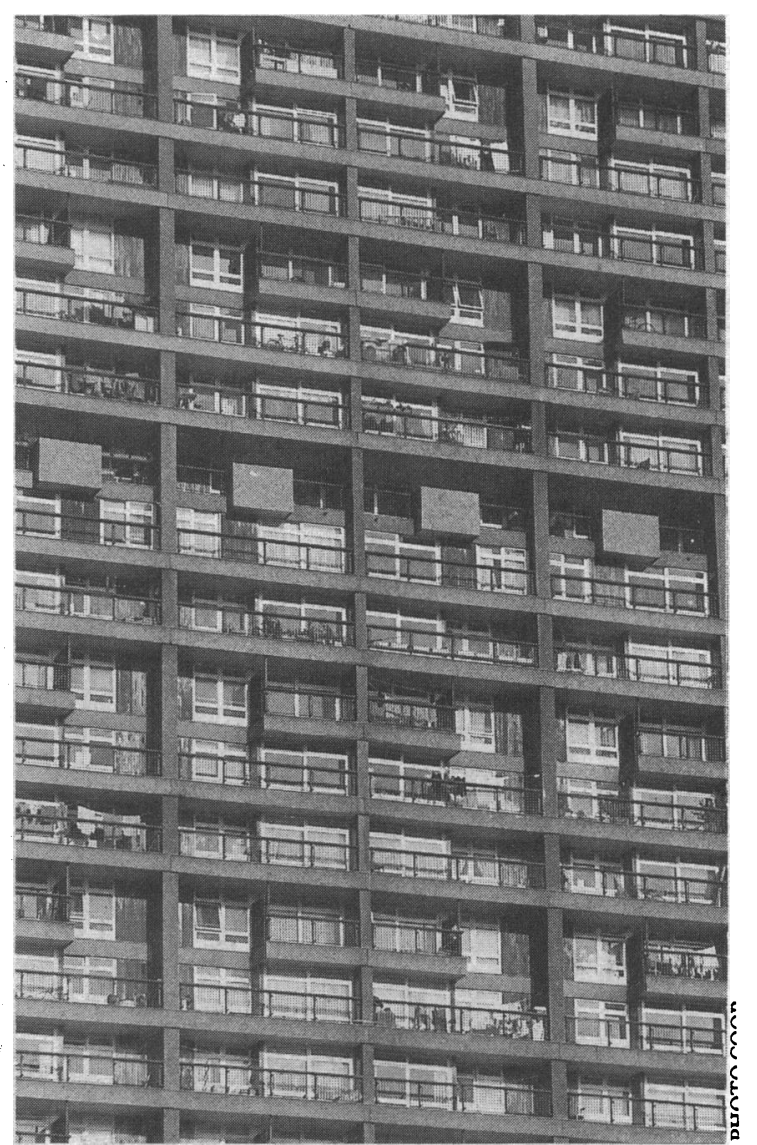

People living in tower blocks may be bombarded with noise from all directions 